\section{The UCT Department of Medicine at 90 years - continuity and change}

To the Editor: The Department of Medicine at the University of Cape Town (UCT) has recently celebrated 90 years of its existence. The first Professor of Medicine, Professor A W 'Oubaas' Falconer, from Aberdeen, Scotland, established the then Division of Medicine at the new UCT Medical School in February 1920. He contributed greatly to the establishment of clinical teaching, then at Somerset Hospital. ${ }^{1}$ In 1938 Groote Schuur Hospital (GSH) opened, at which time Falconer retired as Professor of Medicine to become Vice-Chancellor and Principal of UCT.

The legendary combination of Professors Jack Brock and Frank Forman, joint heads of the Department from 1938 to 1954, succeeded Falconer. Medical school student numbers increased, and the emphasis of the Department was naturally on clinical teaching. While Forman inspired generations of medical students in the finest traditions of clinical medicine, Brock, who was appointed Professor of Medicine at the age of 33 years, laid enduring strong foundations for medical research. ${ }^{2}$

In 1954 Professor Brock assumed the sole Headship of the Department. During his term from 1954 to 1970 it expanded through the establishment of specialist clinics and increasing research. This era of expansion arguably represented the Department's golden age. Publications grew from two papers per year in the 1940s to an average of 100 peer-reviewed publications per year by the 1960s.
Specialist clinics, like the Cardiac Clinic established in 1955, fostered innovation and made possible great medical achievements such as the first human heart transplant at GSH. ${ }^{2}$

Professor Stuart Saunders succeeded Brock in 1971 and successfully steered the Department through turbulent times. Professor Bill Hoffenberg was banned for his anti-apartheid activities in 1968 and went into exile. The political repression and unrest of the 1970s significantly impacted on the life and work of the Department, resulting in a major exodus of highly qualified staff in 1977 and 1978 after the 1976 uprisings of schoolchildren against Bantu education.

Chronic health care budget cuts and the flight of staff into the private sector or overseas continued in the era of Professor Solomon Benatar from 1981 to 1999. Professor Benatar stabilised the Department amid an increasingly hostile funding environment. Professor Ralph Kirsch succeeded him in 1999 in a Department that was sound with respect to the quality of clinical teaching, medical service and research output.

In 2006, as the seventh Head, I inherited one of the finest Departments of Medicine in Africa, a tribute to the fighting spirit of Ralph Kirsch and his predecessors in ensuring the survival of academic medicine in Cape Town under difficult conditions. ${ }^{3}$ Today the Department has talented and dedicated men and women who are committed to providing the best clinical care to their patients, produce competent doctors and specialists, and conduct research of international quality (Fig. 1) (also see www.medicine.uct.ac.za).

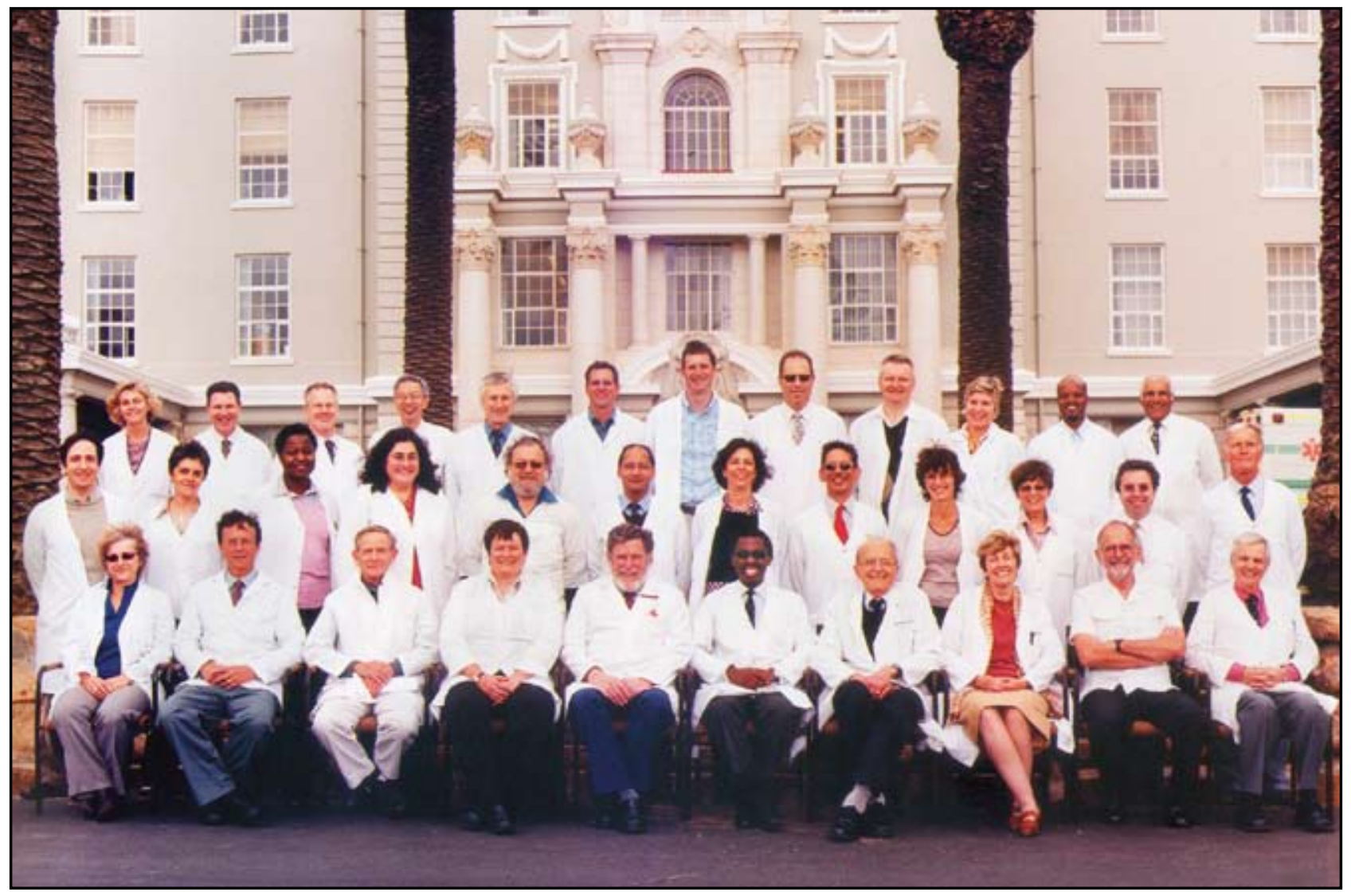

Fig. 1. Consultant staff, Department of Medicine, University of Cape Town and affiliated hospitals, 2008. Back row: Dr G Watermeyer, A/Prof. M Blockman, Dr A McDonald, Dr E Lee Pan, A/Prof. C Swanepoel, Dr P Raubenheimer, A/Prof. M Mandelson, A/Prof. B Rayner, Dr M Sonderup, Dr H van der Plas, Dr M Ntsekhe, Prof. A Kalla. Middle row: Dr G Parolis, Dr D Harwarden, Dr S Kalula, Dr K Cohen, A/Prof. S Ress, A/Prof. M Combrinck, A/Prof. J Heckmann, A/Prof. B Kies, A/Prof. W Spearman, Dr B Buchannan-Lee, Dr I Ross, Dr J Stevens. Front row: Prof. N Levitt, Prof. P Potter, Prof. M Kew, Prof. V Burch, Emeritus Prof. R Kirsch, Prof. B Mayosi (Head), Emeritus Prof. L Opie, Prof. J Seggie, Prof. P Commerford, Emeritus A/Prof. R Scott Millar. 
Over the past four years the Department has transformed to meet the formidable health needs of South Africans. ${ }^{4}$ A larger and stronger Department is required to meet the challenges of a rising disease burden and shortage of health professionals in South Africa. Through active fundraising from public and private sources, the fulltime academic teaching staff (professors, associate professors, senior lecturers and registrars) has increased by 37\% from 109 in 2005 to 149 , and the proportion of black academic staff has increased to nearly $50 \%$.

The new Department of Higher Education and Training clinical training grant enabled us to appoint 20 new senior specialists to assist in teaching undergraduate and postgraduate students. The link between 'town and gown' has been restored by bringing experienced private sector colleagues back into university clinical teaching. The Department increased its publications, which peaked at 250 in 2009, and the number of National Research Foundation-rated researchers increased from five in 2005 to 16 in 2009 (three A-rated), heralding the Department's renaissance.

Major challenges are the severe shortage of beds at GSH and affiliated hospitals and the general under-funding of academic health complexes in South Africa. ${ }^{5}$ Bed occupancy in the medical wards has on occasion been $140 \%$, and patients have waited for a bed in casualty for up to 5 days. In $2009,50 \%$ of casualty admissions waited for longer than 24 hours for a medical ward bed, with a third of patients waiting for over 36 hours. This extreme pressure on tertiary health care services highlights the critical need to reform the governance and funding arrangements of the academic health complexes according to the provisions of the National Health Act of 2004, which were aired in Parliament.

The future of medicine in South Africa requires the restoration of collaboration between universities and the departments of health, education and science and technology to raise the quality of clinical care, teaching and research to meet South Africa's overwhelming health needs. ${ }^{7}$ Remarkable medical advances occurred at GSH in the 1960s, such as the invention of computed tomography by Cormack $^{8}$ and the first human heart transplant by Barnard. ${ }^{9}$ These were engendered by the foresight and vision of the Joint Agreement between UCT and the Cape Provincial Administration, which provided mutually beneficial funding and governance arrangements for clinical care, teaching and research. ${ }^{2}$ Medicine in South Africa requires a new national joint agreement on the governance and funding of the academic health complexes. ${ }^{7}$

\section{Bongani M Mayosi}

7th Head and Professor

Department of Medicine

Groote Schuur Hospital and

University of Cape Town

bongani.mayosi@uct.ac.za

1. Louw JH. In the Shadow of Table Mountain: A History of the University of Cape Town Medical School and its Associated Teaching Hospitals up to 1950, with Glimpses into the Future. Cape Town: Struik, 1969.

2. Benatar SR. Changes, Challenges and Choices in Medicine. Cape Town: University of Cape Town, 1981.

3. Kirsch RE. Academic medicine - what will we leave the next generation? S Afr Med J 1987; 71: 145-148.

4. Chopra M, Lawn JE, Sanders D, et al. Achieving the health Millennium Development Goals for South Africa: challenges and priorities. Lancet 2009; 374: 1023-1031

5. Mayosi BM, Dhai A, Folb P, et al. Revitalising Clinical Research in South Africa: A Study on Clinical Research and Related Training. Pretoria: Academy of Science of South Africa, 2009.

6. Bateman C. Academic health complexes bleeding in 'no man's land'. S Afr Med J 2010; 100: 17-19.

7. Mayosi BM. The Future of Medicine. Cape Town: University of Cape Town, 2007. http://74.125.155.132/scholar?q=cache:wws46LCy58MJ:scholar.google. com/\&hl=en\&as_sdt=2000 (accessed 18 August 2010).

8. Vaughan CL, Mayosi BM. Origins of computed tomography. Lancet 2007; 369: 1168 .

9. Barnard CN. The operation. A human cardiac transplant: an interim report of a successful operation performed at Groote Schuur Hospital, Cape Town. S Afr Med J 1967; 41: 1271-1274. 